Purdue University

Purdue e-Pubs

2019

\title{
On the transient thermal response of thin vapor chamber heat spreaders: governing mechanisms and performance relative to metal spreaders
}

G. Patankar

Purdue University

J.A. Weibel

Purdue University, jaweibel@purdue.edu

S V. Garimella

Purdue University, sureshg@purdue.edu

Follow this and additional works at: https://docs.lib.purdue.edu/coolingpubs

Patankar, G.; Weibel, J. A.; and Garimella, S V., "On the transient thermal response of thin vapor chamber heat spreaders: governing mechanisms and performance relative to metal spreaders" (2019). CTRC Research Publications. Paper 345.

http://dx.doi.org/10.1016/j.ijheatmasstransfer.2019.03.058

This document has been made available through Purdue e-Pubs, a service of the Purdue University Libraries. Please contact epubs@purdue.edu for additional information. 


\title{
On the Transient Thermal Response of Thin Vapor Chamber Heat Spreaders: Governing Mechanisms and Performance Relative to Metal Spreaders
}

\author{
Gaurav Patankar, Justin A. Weibel and Suresh V. Garimella* \\ Cooling Technologies Research Center \\ School of Mechanical Engineering, Purdue University \\ 585 Purdue Mall, West Lafayette, IN 47907 USA
}

\begin{abstract}
Vapor chambers can offer a passive heat spreading solution for thermal management in electronics applications ranging from mobile devices to high-power servers. The steady-state operation and performance of vapor chambers has been extensively explored. However, most electronic devices have inherently transient operational modes. For such applications, it is critical to understand the transient thermal response of vapor chamber heat spreaders and to benchmark their transient performance relative to the known behavior of metal heat spreaders. This study uses a low-cost, 3D, transient semi-analytical transport model to explore the transient thermal behavior of thin vapor chambers. We identify the three key mechanisms that govern the transient thermal response: (1) the total thermal capacity of the vapor chamber governs the rate of increase of the volume-averaged mean temperature; (2) the effective in-plane diffusivity governs the time required for the spatial temperature profile to initially develop; and (3) the effective in-plane conductance of the vapor core governs the range of the spatial temperature variation, and by extension, the steady-state performance. An experiment is conducted using a commercial vapor chamber sample to confirm the governing mechanisms revealed by the transport model; the model accurately predicts the experimental measurements. Lastly, the transient performance of a

*Corresponding author: Tel. 7654945621 ; sureshg@ purdue.edu


vapor chamber relative to a copper heat spreader of the same external dimensions is explored as

a function of the heat spreader thickness and input power. The mechanisms governing the transient behavior of vapor chambers are used to explain the appearance of key performance thresholds beyond which performance is superior to the copper heat spreader. This work provides a foundation for understanding the benefits and limitations of vapor chambers relative to metal heat spreaders in transient operation and may inform the design of vapor chambers for improved transient performance.

Keywords: transient, vapor chamber, heat pipe, heat spreader, transport mechanisms

\section{Nomenclature}

$A, B 1, B 2, C 1, C 2 \quad$ temperature measurement locations

$C_{p} \quad$ specific heat capacity $\left[\mathrm{J} \mathrm{kg}^{-1} \mathrm{~K}^{-1}\right]$

$h \quad$ convection coefficient $\left[\mathrm{W} \mathrm{m}^{-2} \mathrm{~K}^{-1}\right]$

$h_{f g} \quad$ specific enthalpy of vaporization $\left[\mathrm{J} \mathrm{kg}^{-1}\right]$

K $\quad$ permeability $\left[\mathrm{m}^{2}\right]$

$k \quad$ thermal conductivity $\left[\mathrm{W} \mathrm{m}^{-1} \mathrm{~K}^{-1}\right]$

$M_{V C-C u} \quad$ transient performance of a vapor chamber relative to a copper spreader

$\dot{m}^{\prime \prime} \quad$ mass flux rate $\left[\mathrm{kg} \mathrm{m}^{-2} \mathrm{~s}^{-1}\right]$

$P \quad$ pressure $[\mathrm{Pa}]$

$Q \quad$ input power [W]

$R \quad$ specific gas constant $\left[\mathrm{J} \mathrm{kg}^{-1} \mathrm{~K}^{-1}\right]$ 


\begin{tabular}{|c|c|}
\hline$T$ & temperature $[\mathrm{K}]$ \\
\hline$T_{\text {sat }}$ & saturation temperature $[\mathrm{K}]$ \\
\hline$T_{\infty}$ & ambient temperature $[\mathrm{K}]$ \\
\hline$t$ & time $[\mathrm{s}]$ \\
\hline$u$ & $x$-component of velocity $\left[\mathrm{m} \mathrm{s}^{-1}\right]$ \\
\hline$\vec{V}$ & velocity vector $\left[\mathrm{m} \mathrm{s}^{-1}\right]$ \\
\hline$v$ & $y$-component of velocity $\left[\mathrm{m} \mathrm{s}^{-1}\right]$ \\
\hline$w$ & $z$-component of velocity $\left[\mathrm{m} \mathrm{s}^{-1}\right]$ \\
\hline$x$ & $x$-coordinate (length) direction $[\mathrm{m}]$ \\
\hline$y$ & $y$-coordinate (width) direction $[\mathrm{m}]$ \\
\hline z & $z$-coordinate (thickness) direction $[\mathrm{m}]$ \\
\hline
\end{tabular}

\section{Greek}

$\begin{array}{ll}\delta_{\text {vap }} & \text { vapor-core thickness }[\mathrm{m}] \\ \theta & \text { temperature relative to the ambient }\left(T-T_{\infty}\right)[\mathrm{K}] \\ \mu & \text { viscosity }[\mathrm{Pa} \mathrm{s}] \\ \rho & \text { density }\left[\mathrm{kg} \mathrm{m}^{-3}\right] \\ \sigma & \text { accommodation coefficient }[-] \\ \phi & \text { porosity }[-]\end{array}$

\section{Subscript}

A

$B-C$

$\mathrm{Cu}$ thermocouple location $A$

difference in values between thermocouple locations $B$ and $C$ copper spreader 


$\begin{array}{ll}\text { avg } & \text { average surface based on the } 5 \text { thermocouple location measurements } \\ \text { eff } & \text { effective wick property } \\ \text { int } & \text { wick-vapor interface } \\ l & \text { liquid phase } \\ m & \text { volume-averaged } \\ p & \text { evaporator maximum } \\ p-m & \text { difference in value between evaporator maximum and volume-averaged } \\ V C & \text { vapor chamber } \\ v a p & \text { vapor core }\end{array}$




\section{Introduction}

A vapor chamber is a phase-change-driven passive heat spreading device. A typical design consists of a hollow chamber with a liquid-saturated porous wick lining its inner surface enclosing a central vapor core. The operation of a vapor chamber is illustrated in Figure 1. A localized heat input on the outer surface of the chamber is conducted through the wall causing evaporation at the wick-vapor interface. Localized vapor generation causes vapor to flow away from the heat input and into the vapor core. The vapor condenses onto the opposing (colder) wick-vapor interface, and the heat is rejected from the condenser surface. Capillary forces in the porous wick draw the condensed liquid back towards the heat input region, enabling continuous passive operation.

Heat spreading provides a critical function in the thermal management of electronic devices that has, in part, allowed engineers to develop systems operating at ever higher heat loads and densities. Vapor chambers have been extensively studied for this purpose, with potential applications ranging from the low powers $(<10 \mathrm{~W})$ in mobile electronic devices, to the high fluxes $\left(>500 \mathrm{~W} / \mathrm{cm}^{2}\right)$ in radar power amplifiers and high-performance computing systems [1]. Tight space constraints and the need for spreading of transient heat loads are common in these applications. For example, mobile electronic devices experience low heat loads during idle operation with intermittent high-power bursts to execute functions such as video recording; the internal thickness allotted for thermal management and heat spreading is less than a millimeter.

Previous work in the design of vapor chambers has focused on improving their steady-state thermal performance [2-10]. Many studies have identified the important transport mechanisms in a vapor chamber operating at steady state and accordingly proposed designs to improve performance under these conditions. Prasher et al. [11] developed a resistance-network-based 
model for heat pipes, in which the transport processes in the different sections of the wall, wick, and vapor core are assigned thermal resistances. This model reveals that the resistance across the evaporator wick is most significant for vapor chambers subjected to localized, high-heat-flux inputs. Hence, considerable design efforts [5-10, 12-19] have been targeted at achieving a low resistance during evaporation or capillary-fed boiling in this region of the wick. Recent work by Yadavalli et al. [20] revealed the performance-governing mechanisms for thin vapor chambers operating at low powers; at extremely low thicknesses, the thermal resistance in the vapor core was shown to limit the vapor chamber performance relative to metal heat spreader. This understanding was used in our previous studies for designing the condenser-side wick [4] and selecting the working fluid [21] in ultra-thin vapor chambers, for low-power, hand-held applications.

Several studies have considered the transient behavior of heat pipes and vapor chambers. ElGenk and Lianmin [22] experimentally studied the heat-up and cool-down of a heat pipe under a range of evaporator-side input powers and condenser-side coolant flow rates, concluding that the transient vapor temperature profiles could be locally represented by an exponential function in the cases investigated. Tournier and El-Genk [23] developed a finite-volume-based model to simulate the mass, momentum and thermal transport in the vapor chamber wick to predict pooling of the liquid phase at the condenser. Zhu and Vafai [24] developed a model for heat spreading from a central heater in disk-shaped and rectangular vapor chambers. The analytical model solved for 1D transient conduction in the vapor chamber wall and wick while the quasisteady vapor hydrodynamics was modeled using an assumed spatial velocity profile. The model was used to simulate the startup process of a vapor chamber in terms of the transient temperature and velocity fields. Harmand et al. [25] developed a finite-volume-based transport model to 
predict the transient behavior of rectangular vapor chambers. The model was validated against experiments, and the model capabilities were then demonstrated under several different heating configurations (spatial and temporal). These transient analyses of vapor chambers and others in the literature ([26-30]) do not attempt to identify the key transport mechanisms that govern the transient response of the vapor chamber. The goal of the current study is to extract an understanding of these transient governing mechanisms in vapor chambers relative to transient conduction in solid metal heat spreaders, so as to facilitate rational design of vapor chambers for improved relative transient performance.

In this work, our time-stepping analytical model for vapor chamber transport [31] is used to simulate the transient behavior of a vapor chamber and a solid copper heat spreader. Comparison of the temporal temperature fields in the two devices is used to identify and understand the key mechanisms that govern the transient behavior and performance of vapor chambers. Experiments are conducted with a commercial vapor chamber and compared to predictions from the model to demonstrate the key governing mechanisms identified. Lastly, the transient performance of a vapor chamber relative to a copper heat spreader of the same external dimensions is explored as a function of two key parameters, namely the heat spreader thickness and input power. Thresholds are identified beyond which the vapor chamber offers improved performance relative to the copper heat spreader. The relationship between the key governing mechanisms and the transient performance thresholds is established.

\section{Time-stepping analytical model for vapor chamber transport}

The time-stepping analytical model we previously developed [31] is used for simulating vapor chamber transient behavior. This 3D transient transport model can be used for simulating 
rectangular geometries of the vapor chamber wall, wick, and vapor core, in a configuration where the wick lines the inner surface of the wall and encloses the vapor core as shown in Figure 1. The model allows arbitrarily shaped and located time-varying heat inputs to be specified on the faces. The mass, momentum, and energy transport are solved in the wall, wick, and vapor core of the vapor chamber. The phase change process is simulated at the wick-vapor interface. The model outputs are 3D transient fields of temperature, pressure and velocity.

The governing equations for the mass, momentum and energy transport, before simplification, are given below.

$$
\begin{gathered}
\frac{\partial u}{\partial x}+\frac{\partial v}{\partial y}+\frac{\partial w}{\partial z}=0 \\
\rho \frac{\partial \vec{V}}{\partial t}+\rho\left(u \frac{\partial \vec{V}}{\partial x}+v \frac{\partial \vec{V}}{\partial y}+w \frac{\partial \vec{V}}{\partial z}\right) \\
=-\nabla(\phi P)+\mu\left(\frac{\partial^{2} \vec{V}}{\partial x^{2}}+\frac{\partial^{2} \vec{V}}{\partial y^{2}}+\frac{\partial^{2} \vec{V}}{\partial z^{2}}\right)-\frac{\mu \phi}{K} \vec{V} \\
\left(\rho C_{P}\right)_{e f f}\left(\frac{\partial T}{\partial t}\right)+\left(\rho C_{P}\right)_{l}\left(u \frac{\partial T}{\partial x}+v \frac{\partial T}{\partial y}+w \frac{\partial T}{\partial z}\right) \\
=k_{e f f}\left(\frac{\partial^{2} T}{\partial x^{2}}+\frac{\partial^{2} T}{\partial y^{2}}+\frac{\partial^{2} T}{\partial z^{2}}\right)
\end{gathered}
$$

In the vapor core, the porosity $\phi$ is 1 and the permeability $K$ is $\infty$. For the wick, $k_{\text {eff }}$ is the effective conductivity of the porous medium, while in the wall and vapor core, $k_{\text {eff }}$ corresponds to the respective material thermal conductivity. For the wick and the vapor core, $\left(\rho C_{P}\right)_{l}$ is the fluid volumetric heat capacity, while for the wall, $\left(\rho C_{P}\right)_{l}$ is set to zero; $\left(\rho C_{P}\right)_{e f f}$ is the effective volumetric heat capacity of the three regions, given by: 
for the wick, $\left(\rho C_{P}\right)_{e f f}=\phi\left(\rho C_{P}\right)_{l}+(1-\phi)\left(\rho C_{P}\right)_{s}$,

for the wall, $\left(\rho C_{P}\right)_{\text {eff }}=\left(\rho C_{P}\right)_{\text {wall }}$, and

for the vapor core, $\left(\rho C_{P}\right)_{e f f}=\left(\rho C_{P}\right)_{v a p}$,

where $\left(\rho C_{P}\right)_{s}$ is the volumetric heat capacity of the solid material of the porous wick.

The mass flux rate due to phase change at the wick-vapor interface is evaluated using the difference between the local interface temperature and the local vapor-core saturation temperature [32] as:

$$
\dot{m}^{\prime \prime}=\frac{2 \sigma}{2-\sigma} \frac{h_{f g} \rho_{\text {vap }}}{T_{\text {vap }}^{1.5}}\left(\frac{1}{2 \pi R}\right)^{0.5}\left(T_{\text {int }}-T_{\text {sat }}\right) .
$$

The value of $\sigma$ is chosen to be 0.03 [33]. The saturation temperature in the vapor core is computed using the Clausius-Clapeyron equation

$$
\frac{d P_{v a p}}{d T_{\text {sat }}}=\frac{h_{f g} P_{v a p}}{R T_{s a t}^{2}} .
$$

The model simplifies the governing equations using scaling analysis and assumed temperature profiles along the thickness to allow solution at low computational cost [31]. The errors introduced by these simplifications, in terms of the temperature and pressure fields, were estimated to be low for cases ranging from low- to high-power applications. The final set of differential equations (see [31]) are solved analytically in space and numerically in time. This time-stepping analytical model was validated against a finite-volume-based numerical model for cases at low and high powers. The computational cost was shown to be 3-4 orders of magnitude lower than the finite-volume based model, without significant loss of generality and accuracy. 
This time-stepping analytical model is chosen for the current study as it allows a large number of cases to be evaluated over a wide range of parameters at a tractable computational cost. Simulations are run using a custom script that implements the model in the commercial software MATLAB [34].

\section{Mechanisms governing vapor chamber transient behavior}

\subsection{Numerical simulation case details}

A vapor chamber and a copper spreader of identical external geometry are simulated to observe their transient response to a step heat input. A comparison of these two cases is used to obtain insight into the mechanisms governing the behavior of the vapor chamber.

Heat spreading in a vapor chamber can occur through vapor spreading in the vapor core, heat diffusion in the wick, and heat diffusion in the solid walls. The heat diffusion in the wick is negligible compared to the other processes and hence is neglected in the model [31]. In this demonstration, the vapor chamber has walls of negligible thickness. Taking a case where the wall thickness is negligible allows heat spreading in the vapor core, the mechanism specific to vapor chambers, to be isolated. This creates a stark contrast between the vapor chamber and the copper spreader behavior, which helps in distinguishing the unique mechanisms governing the transient response of the vapor chamber from the commonly understood mechanism of thermal diffusion in solids.

The geometry and boundary conditions of the simulated vapor chamber and copper spreader are shown in Figure 2. The heat spreaders have a rectangular footprint with a length of $80 \mathrm{~mm}$ and a width of $60 \mathrm{~mm}$; the total thickness is $100 \mu \mathrm{m}$. In the vapor chamber, the vapor core has a thickness of $40 \mu \mathrm{m}$, and the two wicks (evaporator-side and condenser-side) have thicknesses of 
$30 \mu \mathrm{m}$ each, and span the entire footprint area. The vapor chamber has a sintered copper wick. Water is used as the working fluid. The properties of water are obtained from the commercial fluid database software REFPROP [35]. The relevant properties of the wick and copper are in Table 1.

The heat spreader (vapor chamber or copper) is subjected to a heat input $Q$ of $4 \mathrm{~W}$, over a 10 $\mathrm{mm} \times 10 \mathrm{~mm}$ square at the center of the evaporator-side face, starting at $t=0 \mathrm{~s}$. The rest of this evaporator-side face is insulated. The opposite condenser-side face has a convective boundary condition with a convection coefficient $h$ of $30 \mathrm{~W} / \mathrm{m}^{2} \mathrm{~K}$ and an ambient temperature $T_{\infty}$ of $300 \mathrm{~K}$. The heat spreader is initially $(t=0 \mathrm{~s})$ at a temperature of $300 \mathrm{~K}$. A time step of $0.2 \mathrm{~s}$ is used for the time-marching.

\subsection{Analysis of the transient thermal response}

Figure 3a shows the temperature response at the center of the evaporator face relative to the ambient, for the vapor chamber and the copper spreader. This peak temperature $\theta_{p}$ in the domain characterizes the effective overall transient thermal resistance of the heat spreader. For the copper spreader, the peak temperature starts at $\theta_{p}=0 \mathrm{~K}$ at $t=0 \mathrm{~s}$ and increases gradually toward a steady state $\left(\theta_{p}=54.2 \mathrm{~K}\right.$ at $\left.t=50 \mathrm{~s}\right)$. For the vapor chamber, the temperature increases more sharply from $\theta_{p}=0 \mathrm{~K}$, reaches a peak at $t=1.8 \mathrm{~s}$, and gradually reduces toward a steady state $\left(\theta_{p}\right.$ $=39.7 \mathrm{~K}$ at $t=50 \mathrm{~s}$ ). To understand the mechanisms underlying this non-intuitive behavior of the vapor chamber, the peak temperature response can be decomposed into the mean (volumeaveraged) temperature $\theta_{m}$, and the difference between the peak and mean temperatures, $\Delta \theta_{p-m}=$ $\theta_{p}-\theta_{m}$ (i.e., peak-to-mean difference). 
The mean temperatures $\theta_{m}$ of the vapor chamber and the copper spreader, plotted in Figure $3 \mathrm{~b}$, both gradually increase from $\theta_{m}=0 \mathrm{~K}$ at $t=0 \mathrm{~s}$ toward a steady state. Note that at steady state, given that an equal amount of power is rejected from the condenser to the ambient in the case of both heat spreaders via identical convective coefficients, the area-averaged condensersurface temperature is the same for both. Also, due to the minimal temperature variation across the thickness, the mean temperature $\theta_{m}$ of both heat spreaders becomes nearly equal at steady state. The rate of increase of this mean temperature $\theta_{m}$ is governed by the mechanism identified as the total thermal capacity of the heat spreader; the vapor chamber temperature increases faster and reaches a steady state sooner than for the copper spreader. This reflects the lower total thermal capacity of the vapor chamber compared to the copper spreader. The total thermal capacity of the vapor chamber is a volume-weighted sum of the thermal capacities of the wick and vapor core. The volumetric thermal capacity of the wick is similar to that of pure copper $\left(4.17 \times 10^{6} \mathrm{~J} / \mathrm{m}^{3} \mathrm{~K}\right.$ for water and $3.42 \times 10^{6} \mathrm{~J} / \mathrm{m}^{3} \mathrm{~K}$ for copper) while the thermal capacity of the vapor is negligibly small. Hence, the volume occupied by the vapor core reduces the total thermal capacity of the vapor chamber compared to a copper spreader, and the volume-averaged mean temperature $\theta_{m}$ of the vapor chamber increases faster than that of the copper spreader.

The peak-to-mean temperature difference $\left(\Delta \theta_{p-m}\right)$ is plotted as a function of time in Figure 3c for both heat spreaders. For the copper spreader, this temperature difference increases up to a constant value of $\Delta \theta_{p-m}=27 \mathrm{~K}$ within a short time period of $t<4.4 \mathrm{~s}$, relative to the time to steady state for the evaporator peak temperature of $\sim 50$ s (Figure 3a). During the initial period before $t=4.4 \mathrm{~s}$, the spatial temperature distribution within the copper spreader is developing via heat diffusion from the heater location in the outward direction. This can be observed in Figure 4a, which shows the profile of the local temperature difference from the mean $\left(\theta-\theta_{m}\right)$ along a 
line on the evaporator-side surface of the copper spreader (dashed line in Figure 2) at different times. At $t=0.4 \mathrm{~s}$, the initial rise in the temperature is limited to a region near the evaporator and the profile is flat (near the initial temperature) outside this region. At a later time of $t=3.2 \mathrm{~s}$, the temperature over the entire length of the surface changes from the initial value. After $t=3.2 \mathrm{~s}$, the temperature profile $\theta-\theta_{m}$ is invariant in time. The time required for $\theta-\theta_{m}$ to develop to this steady profile is governed by the mechanism identified as the effective in-plane diffusivity in the copper spreader, while the constant value of $\Delta \theta_{p-m}=27 \mathrm{~K}$ (Figure 3c) after the initial period is governed by its effective in-plane conductance. For the copper spreader, the effective in-plane diffusivity is simply the thermal diffusivity of copper and the effective in-plane conductance is proportional to the thermal conductivity of copper and the thickness of the spreader.

The peak-to-mean temperature difference $\Delta \theta_{p-m}$ of the vapor chamber (Figure 3c) also goes through an initial period $(t<1.8 \mathrm{~s})$ where it rapidly increases. After this period, unlike for the copper spreader, $\Delta \theta_{p-m}$ gradually reduces with time for the vapor chamber, reaching a steadystate value at a time similar to that for the volume-averaged temperature (Figure $3 b$ ). Investigating the profile of the temperature $\theta-\theta_{m}$ on the evaporator-side of the vapor chamber in Figure $4 \mathrm{~b}$, at time $t=0.4 \mathrm{~s}$ within the initial period, the rise in the temperature is limited to a region near the evaporator and the profile is flat (near the initial temperature) outside this region, as in the case of the copper spreader. At time $t=3.2 \mathrm{~s}$, the temperature over the entire evaporator length has changed from the initial value. The time required for $\theta-\theta_{m}$ to develop to such a profile is governed by the effective in-plane diffusivity of the vapor chamber. In the case of the vapor chamber, this effective-in plane diffusivity is like the ratio of the effective in-plane thermal conductivity of the vapor core and the volumetric capacity of the wick. The similarity in time taken for the development of the $\theta-\theta_{m}$ profile for the copper spreader and the vapor chamber 
indicates that they have a similar effective in-plane diffusivity for this case. However, at later times after $t=3.2 \mathrm{~s}$, the $\theta-\theta_{m}$ profile (Figure $4 \mathrm{~b}$ ) flattens with increasing time, indicating that the effective in-plane conductance increases with time for the vapor chamber, unlike the constant value for the copper spreader. For the vapor chamber, the effective in-plane thermal conductance goes as the product of the effective in-plane thermal conductivity and the thickness of the vapor core. The effective in-plane conductivity of the vapor core is governed by the saturation pressure gradient in the vapor core due to vapor flow; the temperature dependence of the fluid properties causes the saturation pressure/temperature gradient to decrease as the mean temperature $\theta_{m}$ increases with time.

In summary, the above inspection of the transient temperature profiles reveals three key mechanisms governing the transient thermal behavior of a vapor chamber:

1) the total thermal capacity of the vapor chamber governs the rate of increase of the volume-averaged mean temperature, $\theta_{m}$;

2) the effective in-plane diffusivity governs the time required for the spatial temperature profile, $\theta-\theta_{m}$, to initially develop;

3) the effective in-plane conductance of the vapor core governs the magnitude of the spatial variation of temperature $\Delta \theta_{p-m}$, and by extension, the steady-state performance.

\section{Experimental demonstration and comparison with the model}

\subsection{Experimental facility and procedure}

A transient heat spreading experiment is conducted with a thin, commercial vapor chamber. The transient temperature field is characterized in response to a step heat input to demonstrate 
and confirm the key mechanisms identified in Section 3.2. A photograph of the $150 \mathrm{~mm}$-long, 8.5 mm-wide, and $1.8 \mathrm{~mm}$-thick vapor chamber (Novark Technologies) is shown in Figure 5a.

Figure 5c illustrates the experimental test setup, which is designed to isolate the vapor chamber from any object having a significant thermal capacity that would affect the transient heat transport behavior. This approach enables a direct comparison against the model without the confounding effects of external thermal masses.

The vapor chamber is suspended from posts using thin ( $0.2 \mathrm{~mm}$ diameter) steel wires looped around each end. The posts are spaced $130 \mathrm{~mm}$ apart in the direction along the heat spreader length and $95 \mathrm{~mm}$ apart in the transverse direction. The vapor chamber is suspended $130 \mathrm{~mm}$ above an optical breadboard. A central $8.5 \mathrm{~mm}$ length of the vapor chamber is wrapped tightly with a sheathed nichrome wire $(90 \% \mathrm{Ni}, 10 \% \mathrm{Cr} ; 5 \mathrm{ohm})$; thermal grease (Tgrease880, Laird Technologies) is applied between the heat spreader surface and the heater wire. A $30 \mathrm{~V}, 3 \mathrm{~A}$ power supply (GPS-2303, Gw Instek) is attached to the nichrome heater using lead wires. The vapor chamber rejects heat to the ambient via natural convection. The setup is isolated from ambient air currents using a $300 \mathrm{~mm}$-long, $200 \mathrm{~mm}$-wide, and $320 \mathrm{~mm}$-tall rectangular enclosure which is open at the top.

Temperatures on the surface of the vapor chamber are measured using T-type thermocouples. The locations of these temperature measurements are shown in Figure 5b. Location $A$ is in the center of the heated region, locations $B 1$ and $B 2$ are $15 \mathrm{~mm}$ from the ends of the heated region, and $C 1$ and $C 2$ are $40 \mathrm{~mm}$ from the ends of the heated region. The temperature at the heater (location $A$ ) is measured by inserting the thermocouple bead between the wrapped nichrome wire and the heat spreader. All other temperatures are measured by pressing the thermocouple beads into contact with the surface using a small piece of copper foil adhesive tape, taking care to avoid 
any stress on the wire. The thermocouples are wired to a reference junction maintained at $0{ }^{\circ} \mathrm{C}$ (CL122, Omega). The ambient temperature and the reference temperature are measured using RTDs. The current through the nichrome heater is measured using a shunt resistance $(0.01 \mathrm{ohm})$ placed in series; the potential difference across the heater is measured directly. Data are collected and recorded via National Instruments (NI) LabVIEW software at a rate of $3 \mathrm{~Hz}$ using a data acquisition chassis (NI cDAQ-9178) outfitted with modules for thermocouple (NI 9214), voltage (NI 9219), and RTD (NI 9217) measurement inputs.

The thermocouples are all simultaneously calibrated over a temperature range of $30^{\circ} \mathrm{C}$ to 100 ${ }^{\circ} \mathrm{C}$ in steps of $10{ }^{\circ} \mathrm{C}$ using a dry block calibrator (Jupiter 4852, Isotech). The calibration temperature is measured using an RTD. A linear offset from the NIST ITS-90 standard is fitted to the calibration data for each thermocouple. The thermocouple temperature measurements have an uncertainty of $\pm 0.3 \mathrm{~K}$ after this calibration procedure [36].

Initially, the vapor chamber temperature (at all 5 thermocouple locations) is at the ambient value. At $t=0$, a heat input of $3 \mathrm{~W}$ is imposed by turning on the power supply through the control panel. The temperature measurements are recorded till the temperature at location $A$ reaches a steady state.

\subsection{Replication of the experimental conditions in the model}

A comparison between the experiment and the time-stepping analytical model is established by simulating a vapor chamber of the same length and width as the sample tested in the experiments (150 $\mathrm{mm}$ length and $8.5 \mathrm{~mm}$ width). The vapor chamber wall has a thickness of 200 $\mu \mathrm{m}$ to match that of the sample tested. The layout of the wick in the vapor chamber tested does not match with that in the model, i.e. the wick in the vapor chamber tested does not line the inner surface of the wall. Also, the fluid charge volume in the vapor chamber is unknown. Hence, the 
thicknesses of the wicks and the vapor core are estimated inputs to the model to create an equivalent case as the tested sample. The wick, which lines the inner surface of the top and bottom walls of the simulated case, has thickness set to $250 \mu \mathrm{m}$ each, such that the volume of the wick matches that in the physical sample. The wick primarily contributes to the total thermal capacity of the vapor chamber, which drives this method for setting the wick thicknesses. The vapor core thickness is set to $150 \mu \mathrm{m}$ to match the experimental and simulated maximum transient value of the difference between the temperatures at locations $B$ and $C$. This assumption is justified because the vapor core thickness primarily governs the in-plane temperature variations in the vapor chamber. The wall material is copper. A sintered copper wick is used with an assumed value of 0.6 for the porosity. Water is used as the working fluid as in the vapor chamber sample. Step heat inputs of $1.5 \mathrm{~W}$ each are applied at the center of the top and bottom faces of the heat spreaders, totaling to a $3 \mathrm{~W}$ input, over a square heated region of $8.5 \mathrm{~mm} \times 8.5$ $\mathrm{mm}$. The remaining areas of the two faces reject heat to the ambient using a natural convection condition. The convection coefficient is computed based on the local wall temperature using empirical correlations [37]. The empirical correlations are defined for heated plates exposed only on one side. Hence the computed convection coefficient is multiplied by a constant factor to account for the different boundary conditions in the experiment. The factor is calibrated such that the average surface temperature $\left(T_{\text {avg }}\right)$, at steady state, matches between the experiment and the simulation. The average surface temperature $\left(T_{\text {avg }}\right)$ is computed by fitting lines between neighboring thermocouple location temperature measurements $(C 1-B 1, B 1-A, A-B 2, B 2-C 2)$ and taking a constant value from the $C$ locations to the length-wise ends of the heat spreader, equal to the corresponding $C$ location temperature measurement. The ambient temperature is an 
input to the model from the experiments, and the heat spreader is initialized at a uniform temperature equal to the ambient temperature.

\subsection{Comparison of experiments and simulations}

The step input power supply in the experiment is turned on at $t=0 \mathrm{~s}$; the power increases from 0 to $3.0 \mathrm{~W}$ in $1.33 \mathrm{~s}$. The transient temperatures $\theta$, measured at the thermocouple locations, are plotted in Figure 6 for the vapor chamber. The ambient temperature is $24.3{ }^{\circ} \mathrm{C}$. The temperatures gradually increase from the ambient temperature to steady-state values.

Figure 7 and Figure 8 compare the results from the experiment with results from the simulation. The data presented in these figures follow the layouts of Figure 3 and Figure 4, respectively, and are used to confirm the governing mechanisms identified in Section 3.2.

Figure 7a plots the transient variation of the temperature at location $A$ relative to the ambient $\left(\theta_{A}\right)$, indicative of the evaporator temperature. There is a good match between the experiment and simulation for this common metric of vapor chamber performance. Figure $7 \mathrm{~b}$ plots the transient variation of the average surface temperature of the vapor chamber (defined in Section 4.2) relative to the ambient temperature $\left(\theta_{\text {avg }}=T_{a v g}-T_{\infty}\right)$. The match between the experiment and simulation indicates that the simulation accurately models the total thermal capacity of the vapor chamber, which governs the transient variation of $\theta_{\text {avg }}$ as discussed in Section 3.2. Figure 7c plots the transient variation of the length-wise temperature variation in the vapor chamber. The lengthwise temperature variation is represented by the average difference between the temperatures at locations $B$ and $C\left(\Delta \theta_{B-C}=\left[\theta_{B 1}-\theta_{C 1}+\theta_{B 2}-\theta_{C 2}\right] / 2\right)$. As was identified for the transient spatial temperature variation in Figure 3c, the value of $\Delta \theta_{B-C}$ in Figure $7 \mathrm{c}$ increases sharply, and then gradually reduces towards a steady state, for both the experiment and the simulation. The time required for the value of $\Delta \theta_{B-C}$ to peak, governed by the effective in-plane diffusivity of the vapor 
chamber, is on the same order between the experiment and the simulation. Also, the transient profile of $\theta_{B-C}$ after the peak, governed by the effective in-plane conductance of the vapor core, matches well between the experiment and the simulation, all the way till a steady state is attained. Note that the peak value of this transient profile is used to calibrate the vapor-core thickness in the simulation, as discussed in Section 4.2.

Figure $8 \mathrm{a}$ and $\mathrm{b}$ show, for the experiment and the simulation respectively, the temperature difference from the surface average $\left(\theta-\theta_{\text {avg }}\right)$ at the 5 thermocouple locations at different times. Similar to the trends in the transient temperature profile observed in Figure 4b, the temperature first increases in the near-heater region, followed by the outer region, for an initial period of time $\left(t=1-4 \mathrm{~s}\right.$ in Figure 8). At later times $(t=4-30 \mathrm{~s}$ in Figure 8$)$, the profile of $\theta-\theta_{\text {avg }}$ gradually flattens with time. A video showing the transient variation of $\theta$ - $\theta_{\text {avg }}$ at the 5 thermocouple locations in the experiment, plotted along with the simulated profile of $\theta-\theta_{m}$ along the length of the vapor chamber, is included in the supplementary material. The match of these trends between the experiment and simulation further verifies that the effective in-plane diffusivity and effective in-plane conductance govern the development of the spatial temperature profile.

\section{Transient vapor chamber performance relative to a copper spreader}

\subsection{Dependence of relative transient performance on time scale}

In this section, the performance of a vapor chamber is benchmarked against a copper spreader of the same external geometry. The performance is strongly dependent on time scale, with multiple crossovers in the peak temperature between the two spreaders for the chosen case. The reasons for this complex comparative behavior are discussed based on the relative magnitudes of the governing mechanisms underlying the transient thermal behavior. This 
discussion serves as a basis for description to follow of the effects of parameters on the relative performance between the two spreaders (to be discussed in Section 5.2).

The case details for these simulations are the same as considered in Section 3.1, and have a zero wall thickness, with the only difference being that the vapor core thickness is increased from $40 \mu \mathrm{m}$ to $200 \mu \mathrm{m}$. Time step sizes of $0.02 \mathrm{~s}$ and $0.1 \mathrm{~s}$ are used respectively for $t<2 \mathrm{~s}$ and $t$ $>2$ s.

Figure 9 a shows the peak temperature $\theta_{p}$ as a function of time for the vapor chamber and the copper spreader. The plot indicates multiple crossovers between the temperatures. Figure $9 \mathrm{~b}$ shows the corresponding mean temperature $\theta_{m}$, and Figure $9 \mathrm{c}$ the peak-to-mean temperature difference $\Delta \theta_{p-m}$. In Figure $9 \mathrm{~b}$ the mean temperature $\theta_{m}$ is seen to increase faster for the vapor chamber than the copper spreader, owing to its lower total thermal capacity. Figure $9 \mathrm{c}$ indicates that for time $t>0.16 \mathrm{~s}, \Delta \theta_{p-m}$ is much lower for the vapor chamber than the copper spreader, reflecting a higher effective in-plane conductance for the vapor chamber. The higher effective inplane conductance and lower total thermal capacity implies that the vapor chamber has a higher effective in-plane diffusivity. As a result, $\Delta \theta_{p-m}$ increases faster in the vapor chamber in its initial diffusion period $(t<0.1 \mathrm{~s})$, as seen in Figure 9c. The lower effective in-plane conductance of the copper spreader, on the other hand, results in $\Delta \theta_{p-m}$ increasing to a higher value after its initial diffusion period. This causes a crossover in $\Delta \theta_{p-m}$ at $t=0.2 \mathrm{~s}$, and a corresponding crossover in the $\theta_{p}$ profile as well. Because the vapor chamber $\theta_{m}$ increases faster than that of the copper spreader, another crossover in $\theta_{p}$ occurs at $4.9 \mathrm{~s}$. At steady state (not seen in Figure 9), the value of $\theta_{m}$ eventually becomes almost the same for both spreaders and hence the value of $\theta_{p}$ is governed only by $\Delta \theta_{p-m}$. Given the higher value of $\Delta \theta_{p-m}$ at steady state for the copper spreader, 
its $\theta_{p}$ value also is higher than the vapor chamber. This behavior leads to the third crossover at $t$ $=29.4 \mathrm{~s}$.

The existence of these crossovers between the copper spreader and vapor chamber peak evaporator temperature $\theta_{p}$ indicates that the choice of heat spreaders is highly dependent on the time scale of interest. The existence of the multiple crossovers, versus the single crossover in Figure 3, merits the parametric study that follows.

\subsection{Effects of key parameters on the transient performance}

This section investigates the dependence of vapor chamber performance, relative to a copper spreader of equal external dimensions, on the vapor core thickness and input power. The governing mechanisms are sensitive to these two key parameters.

Generally, the total thermal capacity of the vapor chamber is lower than the copper spreader, due to the very low thermal capacity of the vapor core; this contrast increases with increasing vapor core thickness. The effective in-plane conductance of the vapor core increases polynomially with thickness, as has been identified in our previous work [21], versus a linear increase with thickness for the copper spreader. These trends imply that the effective in-plane diffusivity of the vapor chamber (which can be understood as the ratio of the effective in-plane conductivity of the vapor core and the volumetric capacity of the wick as identified in Section 3.2) relative to the copper spreader also increases with vapor-core thickness. The vapor core effective in-plane conductance also increases with increasing mean temperature due to the temperature-dependence of the vapor properties; hence, as the mean temperature increases with time, so does the effective in-plane conductance. Note that the mean temperature of the vapor chamber in the transient regime is always higher due to its lower total thermal capacity compared to the copper spreader. 
Figure 10a (with details at short time-scales shown in Figure 10b) maps the relative transient performance for a range of vapor-core thicknesses as a function of time. The case details for these simulations are the same as described in Section 3.1, except for the vapor core thickness. The evaporator is subjected to a heat input of $4 \mathrm{~W}$. A time step of $0.1 \mathrm{~s}$ is used for the time marching.

The relative performance is presented using a metric defined as

$$
M_{V C-C u}=\ln \left(\frac{\theta_{p, C u}}{\theta_{p, V C}}\right)
$$

where $\theta_{p, V C}$ and $\theta_{p, C u}$ correspond to the peak evaporator temperatures of the vapor chamber and the copper spreader, respectively. A value of zero for $M_{V C-C u}$ corresponds to equal performance for both heat spreaders; this performance threshold is shown in white on the contour scale in Figure 10a and Figure 10b. A positive value, shown in blue, indicates the vapor chamber performs better while a negative value, shown in red, indicates the copper spreader performs better.

Regions on the contour maps in Figure 10a and Figure 10b are identified by numbers 1 to 6 and the governing mechanisms responsible for relative performance in these regions are explained here. In region 1 the vapor-core thickness is small enough that its effective in-plane conductance at all times through steady-state is less than that of the copper spreader, causing a high $\Delta \theta_{p-m}$. Given that the vapor chamber also always has a higher $\theta_{m}$ than the copper spreader, the vapor chamber performs worse in this region. This trend was previously identified in the steady-state analysis conducted by Yadavalli et al. [20]. Region 2 also exists due to this lower effective in-plane conductance. However, it extends to higher thicknesses, because at shorter times, low temperatures lead to lower values of effective in-plane conductance for the vapor 
chamber. Region 3 corresponds to the initial diffusion period; the vapor chamber performs worse because the higher effective in-plane diffusivity of the vapor chamber leads to a faster effective in-plane diffusion process and hence a faster initial increase in temperature. The vapor chamber performs better than the copper spreader in region 4 due to its high effective in-plane conductance due to the vapor core. At these early times, the mean temperatures of the vapor chamber and copper spreader have not yet risen much above ambient, and the differences in performance are instead attributed to the peak-to-mean temperature difference $\Delta \theta_{p-m}$, which is governed by the vapor core effective in-plane conductance. In region 5, the vapor chamber mean temperature $\theta_{m}$ increases faster than that of the copper spreader due to its relatively low total thermal capacity, causing worse relative performance. With increasing vapor core thickness, the total thermal capacity of the copper spreader increases, which heats up slower, and the right-side border of region 5 extends to a higher time. At the later times in region 6 (extending to steady state), the values of $\theta_{m}$ are similar for both spreaders. However, the vapor chamber has a higher effective in-plane conductance than the copper spreader, leading to a lower $\Delta \theta_{p-m}$ and hence better performance.

Contour maps of the performance of the vapor chamber relative to the copper spreader are plotted in supplementary materials (Appendix A) for two more conditions; the first accounts for the effects of including the vapor chamber walls, and the second accounts for a high heat input of $100 \mathrm{~W}$. Adding a wall primarily dampens the contrast between the performance of the vapor chamber and the copper spreader. In the second case, region 4 disappears.

In Figure 10c and Figure 10d, the effects of input power on the relative transient performance are explored for a range of vapor core thicknesses; the contour shading is omitted from the maps and instead the threshold lines $\left(M_{V C-C u}=0\right)$ are drawn as solid lines for each power level. 
Increasing the input power increases the entire temporal profile of the mean temperature $\theta_{m}$, and hence the vapor core effective in-plane conductance. This is the primary cause behind the changes in the relative performance thresholds with increasing power, which generally expand the size of the operating regions in which the vapor chamber performance is better than copper.

Identification of these mechanistic performance thresholds is critical for understanding the use conditions under which vapor chambers are favorable relative to copper spreaders. For steady-state design, there is a single threshold value at some vapor-core thickness at which this distinction is possible, as had been previously identified from steady-state analysis [20]. In the transient regime, however, we reveal that the time scale of operation is critical in determining the non-trivial and unintuitive trends in relative performance. For example, for the case investigated in Figure 10a and Figure 10b, for vapor core thicknesses in the range of 50-100 $\mu \mathrm{m}$, the use of a vapor chamber is favorable only for time-scales that are much longer than $5 \mathrm{~s}$. For vapor-core thicknesses in the range of 200-300 $\mu \mathrm{m}$ use of vapor chambers is favorable for time scales less than 2-4 s or greater than $30-50 \mathrm{~s}$, but not in between. These results demonstrate that the existing design norms regarding the relative advantage of vapor chambers over metal spreaders, developed on the premise of steady operation and associated analyses, are insufficient. A more complex set of design criteria emerges from these transient thresholds that must be considered in the implementation of vapor chamber heat spreaders for thermal management in applications having transient power variations.

\section{Conclusions}

The mechanisms governing the transient thermal response of a vapor chamber are identified using a low-cost, 3D, and transient vapor chamber transport model. Conclusions from this 
analysis are corroborated with experiments conducted using a commercial vapor chamber. The vapor chamber transport model is used to compare the transient thermal response of a vapor chamber with that of a solid copper spreader. The performance of both heat spreader types is analyzed based on the peak evaporator temperature. The decomposition of this temperature into its key components, namely the volume-averaged mean temperature and the peak-to-mean temperature difference, leads to the identification of three key mechanisms that govern the transient thermal response of vapor chambers: (1) the total thermal capacity of the vapor chamber governs the rate of increase of the volume-averaged mean temperature $\theta_{m}$, (2) the effective in-plane diffusivity governs the time required for the initial development of the spatial temperature profile $\theta-\theta_{m}$, and (3) the effective in-plane conductance of the vapor core governs the magnitude of the spatial variation of temperature $\Delta \theta_{p-m}$, and by extension, its steady-state performance.

The vapor chamber transport model is also used to benchmark the transient performance of a vapor chamber against a solid copper spreader for a range of vapor-core thicknesses and input powers. The relative performance of a vapor chamber strongly depends on the operating parameters and the time scale of operation. Relative performance is mapped over the parametertime space and regions are identified in which the vapor chamber performs better (or worse) than the copper spreader; reasons for the existence of these regions are explained based on the governing mechanisms.

This work serves as a foundation in understanding the benefits and limitations of using vapor chambers for thermal management under transient conditions and for designing vapor chambers for improved transient performance. 


\section{Acknowledgement}

Financial support for this work provided by members of the Cooling Technologies Research

Center, a graduated National Science Foundation Industry/University Cooperative Research Center at Purdue University, is gratefully acknowledged. Donation of the vapor chamber tested in this work by Novark Technologies is gratefully acknowledged.

\section{Appendix A. Supplementary material}

Supplementary data associated with this article can be found in the online version (insert link here).

\section{References}

[1] J. A. Weibel and S. V. Garimella, "Recent Advances in Vapor Chamber Transport Characterization for High-Heat-Flux Applications," in Advances in Heat Transfer, vol. 45, pp. 209-301, 2013.

[2] C. Ding, G. Soni, P. Bozorgi, B. D. Piorek, C. D. Meinhart, and N. C. MacDonald, "A Flat Heat Pipe Architecture Based on Nanostructured Titania," Journal of Microelectromechanical Systems, vol. 19, no. 4, pp. 878-884, 2010.

[3] R. Lewis, S. Xu, L. Liew, C. Coolidge, R. Yang, and Y. Lee, “Thin Flexible Thermal Ground Planes: Fabrication and Scaling Characterization," Journal of Microelectromechanical Systems, vol. 24, no. 6, pp. 2040-2048, 2015.

[4] G. Patankar, J. A. Weibel, and S. V. Garimella, "Patterning the Condenser-Side Wick in Ultra-Thin Vapor Chamber Heat Spreaders to Improve Skin Temperature Uniformity of Mobile Devices," International Journal of Heat and Mass Transfer, vol. 101, pp. 927-936, 2016.

[5] Y. Zhao and C.-L. Chen, "An Investigation of Evaporation Heat Transfer in Sintered Copper Wicks with Microgrooves," in 2006 ASME International Mechanical Engineering Congress and Exposition, (IMECE 2006), Chicago, IL, USA, pp. 177-181, 2006.

[6] T. Semenic and I. Catton, "Experimental Study of Biporous Wicks for High Heat Flux Applications," International Journal of Heat and Mass Transfer, vol. 52, no. 21-22, pp. 5113-5121, 2009.

[7] J. A. Weibel and S. V. Garimella, "Visualization of Vapor Formation Regimes during Capillary-Fed Boiling in Sintered-Powder Heat Pipe Wicks," International Journal of Heat and Mass Transfer, vol. 55, no. 13-14, pp. 3498-3510, 2012.

[8] Y. S. Ju, M. Kaviany, Y. Nam, S. Sharratt, G. S. Hwang, I. Catton, E. Fleming, and P. Dussinger, "Planar Vapor Chamber with Hybrid Evaporator Wicks for the Thermal 
Management of High-Heat-Flux and High-Power Optoelectronic Devices," International Journal of Heat and Mass Transfer, vol. 60, pp. 163-169, 2013.

[9] Y. Peng, W. Liu, B. Liu, J. Liu, K. Huang, L. Wang, and W. Chen, "The Performance of the Novel Vapor Chamber Based on the Leaf Vein System," International Journal of Heat and Mass Transfer, vol. 86, pp. 656-666, 2015.

[10] S. Sudhakar, J. A. Weibel, and S. V. Garimella, "An Area-Scalable Two-Layer Evaporator Wick Concept for High-Heat-Flux Vapor Chambers," in 2017 16th IEEE Intersociety Conference on Thermal and Thermomechanical Phenomena in Electronic Systems (ITherm), Orlando, FL, USA, pp. 537-546, 2017.

[11] R. S. Prasher, "A Simplified Conduction Based Modeling Scheme for Design Sensitivity Study of Thermal Solution Utilizing Heat Pipe and Vapor Chamber Technology," Journal of Electronic Packaging, vol. 125, no. 3, pp. 378-385, 2003.

[12] G. S. Hwang, Y. Nam, E. Fleming, P. Dussinger, Y. S. Ju, and M. Kaviany, "Multi-Artery Heat Pipe Spreader: Experiment," International Journal of Heat and Mass Transfer, vol. 53, no. 13-14, pp. 2662-2669, 2010.

[13] J. A. Weibel, S. V. Garimella, and M. T. North, "Characterization of Evaporation and Boiling from Sintered Powder Wicks Fed by Capillary Action," International Journal of Heat and Mass Transfer, vol. 53, no. 19-20, pp. 4204-4215, 2010.

[14] Q. Cai and Y.-C. Chen, "Investigations of Biporous Wick Structure Dryout," Journal of Heat Transfer, vol. 134, no. 2, pp. 021503-021503, 2011.

[15] D. Ćoso, V. Srinivasan, M.-C. Lu, J.-Y. Chang, and A. Majumdar, "Enhanced Heat Transfer in Biporous Wicks in the Thin Liquid Film Evaporation and Boiling Regimes," Journal of Heat Transfer, vol. 134, no. 10, p. 101501, 2012.

[16] A. S. Kousalya, J. A. Weibel, S. V. Garimella, and T. S. Fisher, "Metal Functionalization of Carbon Nanotubes for Enhanced Sintered Powder Wicks," International Journal of Heat and Mass Transfer, vol. 59, pp. 372-383, 2013.

[17] J. W. Palko, C. Zhang, J. D. Wilbur, T. J. Dusseault, M. Asheghi, K. E. Goodson, and J. G. Santiago, "Approaching the Limits of Two-Phase Boiling Heat Transfer: High Heat Flux and Low Superheat," Applied Physics Letters, vol. 107, no. 25, p. 253903, 2015.

[18] T. Liu, S. Lingamneni, J. Palko, M. Asheghi, and K. E. Goodson, "Optimization of Hybrid Wick Structures for Extreme Spreading in High Performance Vapor Chambers," in 2016 15th IEEE Intersociety Conference on Thermal and Thermomechanical Phenomena in Electronic Systems (ITherm), Las Vegas, NV, USA, pp. 30-36, 2016.

[19] M. R. Shaeri, D. Attinger, and R. W. Bonner, "Vapor Chambers with Hydrophobic and Biphilic Evaporators in Moderate to High Heat Flux Applications," Applied Thermal Engineering, vol. 130, pp. 83-92, 2018.

[20] Y. Yadavalli, J. A. Weibel, and S. V. Garimella, "Performance-Governing Transport Mechanisms for Heat Pipes at Ultrathin Form Factors," IEEE Transactions on Components, Packaging and Manufacturing Technology, vol. 5, no. 11, pp. 1618-1627, 2015.

[21] G. Patankar, J. A. Weibel, and S. V. Garimella, "Working-Fluid Selection for Minimized Thermal Resistance in Ultra-Thin Vapor Chambers," International Journal of Heat and Mass Transfer, vol. 106, pp. 648-654, 2017.

[22] M. S. El-Genk and H. Lianmin, "An Experimental Investigation of the Transient Response of a Water Heat Pipe," International Journal of Heat and Mass Transfer, vol. 36, no. 15, pp. 3823-3830, 1993. 
[23] J.-M. Tournier and M. S. El-Genk, "A Heat Pipe Transient Analysis Model," International Journal of Heat and Mass Transfer, vol. 37, no. 5, pp. 753-762, 1994.

[24] N. Zhu and K. Vafai, "Analytical Modeling of the Startup Characteristics of Asymmetrical Flat-Plate and Disk-Shaped Heat Pipes," International Journal of Heat and Mass Transfer, vol. 41, no. 17, pp. 2619-2637, 1998.

[25] S. Harmand, R. Sonan, M. Fakès, and H. Hassan, "Transient Cooling of Electronic Components by Flat Heat Pipes," Applied Thermal Engineering, vol. 31, no. 11-12, pp. 1877-1885, 2011.

[26] U. Vadakkan, S. V. Garimella, and J. Y. Murthy, "Transport in Flat Heat Pipes at High Heat Fluxes from Multiple Discrete Sources," Journal of Heat Transfer, vol. 126, no. 3, pp. 347354, 2004.

[27] Y. Xuan, Y. Hong, and Q. Li, "Investigation on Transient Behaviors of Flat Plate Heat Pipes," Experimental Thermal and Fluid Science, vol. 28, no. 2-3, pp. 249-255, 2004.

[28] S. Murer, P. Lybaert, L. Gleton, and A. Sturbois, "Experimental and Numerical Analysis of the Transient Response of a Miniature Heat Pipe," Applied Thermal Engineering, vol. 25, no. 16, pp. 2566-2577, 2005.

[29] R. Sonan, S. Harmand, J. Pellé, D. Leger, and M. Fakès, "Transient Thermal and Hydrodynamic Model of Flat Heat Pipe for the Cooling of Electronics Components," International Journal of Heat and Mass Transfer, vol. 51, no. 25-26, pp. 6006-6017, 2008.

[30] M. Famouri, M. M. Abdollahzadeh, A. Abdulshaheed, G. Huang, G. Carbajal, and C. Li, "Transient Analysis of a Cylindrical Heat Pipe Considering Different Wick Structures," in ASME 2016 Heat Transfer Summer Conference, p. V002T08A023, 2016.

[31] G. Patankar, J. A. Weibel, and S. V. Garimella, "A Validated Time-Stepping Analytical Model for 3D Transient Vapor Chamber Transport," International Journal of Heat and Mass Transfer, vol. 119, pp. 867-879, 2018.

[32] V. P. Carey, Liquid-Vapor Phase-Change Phenomena. Washington (D.C.), USA: Hemisphere Pub. Corp, 1992.

[33] R. Marek and J. Straub, "Analysis of the Evaporation Coefficient and the Condensation Coefficient of Water," International Journal of Heat and Mass Transfer, vol. 44, no. 1, pp. 39-53, 2001.

[34] MATLAB Release 2017a. Natick, Massachusetts, United States: The MathWorks, Inc.

[35] E. W. Lemmon, M. L. Huber, and M. O. McLinden, NIST Standard Reference Database 23: Reference Fluid Thermodynamic and Transport Properties-REFPROP. Gaithersburg: National Institute of Standards and Technology, Standard Reference Data Program, 2013.

[36] G. Patankar, S. Mancin, J. A. Weibel, S. V. Garimella, and M. A. MacDonald, "A Method for Thermal Performance Characterization of Ultrathin Vapor Chambers Cooled by Natural Convection," Journal of Electronic Packaging, vol. 138, no. 1, p. 010903, 2016.

[37] F. P. Incropera, D. P. Dewitt, T. L. Bergman, and A. S. Lavine, Fundamentals of Heat and Mass Transfer. Hoboken, NJ, USA: John Wiley \& Sons, 2007. 


\section{List of Figures}

Figure 1. Illustration of the typical geometry, internal layout, and operation of a vapor chamber.

Figure 2. Geometry (not to scale) and boundary conditions for the transient heat spreading simulations showing (a) a section view for the copper spreader case, (b) a section view for the vapor chamber case, and (c) a bottom view of the evaporator-side that is common to both cases.

Figure 3. Comparison between the vapor chamber and the copper spreader simulation results $\left(\delta_{\text {vap }}=40 \mu \mathrm{m}\right)$ showing the temporal variation of the (a) peak temperature $\theta_{p}$, (b) volumeaveraged mean temperature $\theta_{m}$, and (c) difference between the peak and mean temperatures $\Delta \theta_{p-m}$ $=\theta_{p}-\theta_{m}$

Figure 4. The profile of local temperature difference from the mean $\left(\theta-\theta_{m}\right)$ along a line on the evaporator-side surface of the heat spreader (dashed line in Figure 2c) at different times, for (a) the copper spreader and (b) the vapor chamber.

Figure 5. (a) Photograph of the vapor chamber sample in top view, (b) diagram of the locations of the thermocouple beads and heated length, and (c) illustration of the experimental test setup.

Figure 6. Experimental measurements of the temperature $\theta$ at the five thermocouple locations as a function of time.

Figure 7. Comparison of the experiment and simulation: (a) temperature at thermocouple location $A\left(\theta_{A}\right)$, (b) average surface temperature relative to the ambient temperature $\left(\theta_{\text {avg }}\right)$, and (c) the average difference between the temperatures at $B$ and $C\left(\Delta \theta_{B-C}\right)$.

Figure 8. Vapor chamber local surface temperatures difference from the average surface temperature $\left(\theta-\theta_{\text {avg }}\right)$ at the thermocouple locations at different times from (a) the experiment and (b) the simulation.

Figure 9. Comparison between the vapor chamber and the copper spreader simulation results $\left(\delta_{\text {vap }}=200 \mu \mathrm{m}\right.$ ) showing the temporal evolution of (a) peak temperature $\theta_{p}$, (b) volume-averaged mean temperature $\theta_{m}$, and (c) difference between the peak and mean temperatures $\Delta \theta_{p-m}=\theta_{p}-\theta_{m}$

Figure 10. Contour plot of the metric for the thermal performance of a vapor chamber relative to a copper spreader $\left(M_{V C-C u}\right)$, for a range of vapor core thicknesses, and as a function of time for (a) $t<100 \mathrm{~s}$ and (b) a zoomed-in view for $t<5 \mathrm{~s}$. Threshold lines $\left(M_{V C-C u}=0\right)$ for the thermal performance of a vapor chamber relative to that of a copper spreader as a function of time for a range of vapor core thicknesses at different input powers in the range (c) $t<100 \mathrm{~s}$ and (d) a zoomed-in view for $t<5 \mathrm{~s}$. 


\section{List of Tables}

Table 1. Copper and wick properties. 
Table 1. Copper and wick properties.

\begin{tabular}{l|l}
\hline \hline Property & Value \\
\hline Wick effective thermal conductivity $\left(k_{e f f}\right)$ & $40 \mathrm{~W} / \mathrm{mK}$ \\
Copper volumetric thermal capacity & $3.42 \times 10^{6} \mathrm{~J} / \mathrm{m}^{3} \mathrm{~K}$ \\
$\left(\rho C_{P}\right)_{s}$ & \\
Wick porosity $(\phi)$ & 0.6 \\
Copper thermal conductivity $(k)$ & $387.6 \mathrm{~W} / \mathrm{mK}$ \\
\hline \hline
\end{tabular}




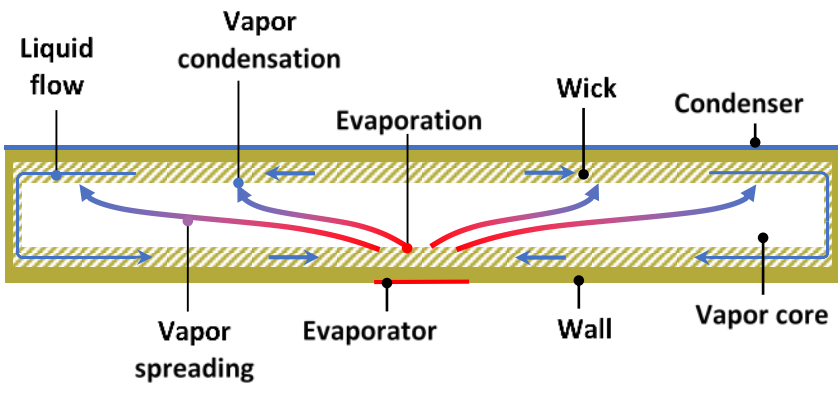

Figure 1. Illustration of the typical geometry, internal layout, and operation of a vapor chamber. 

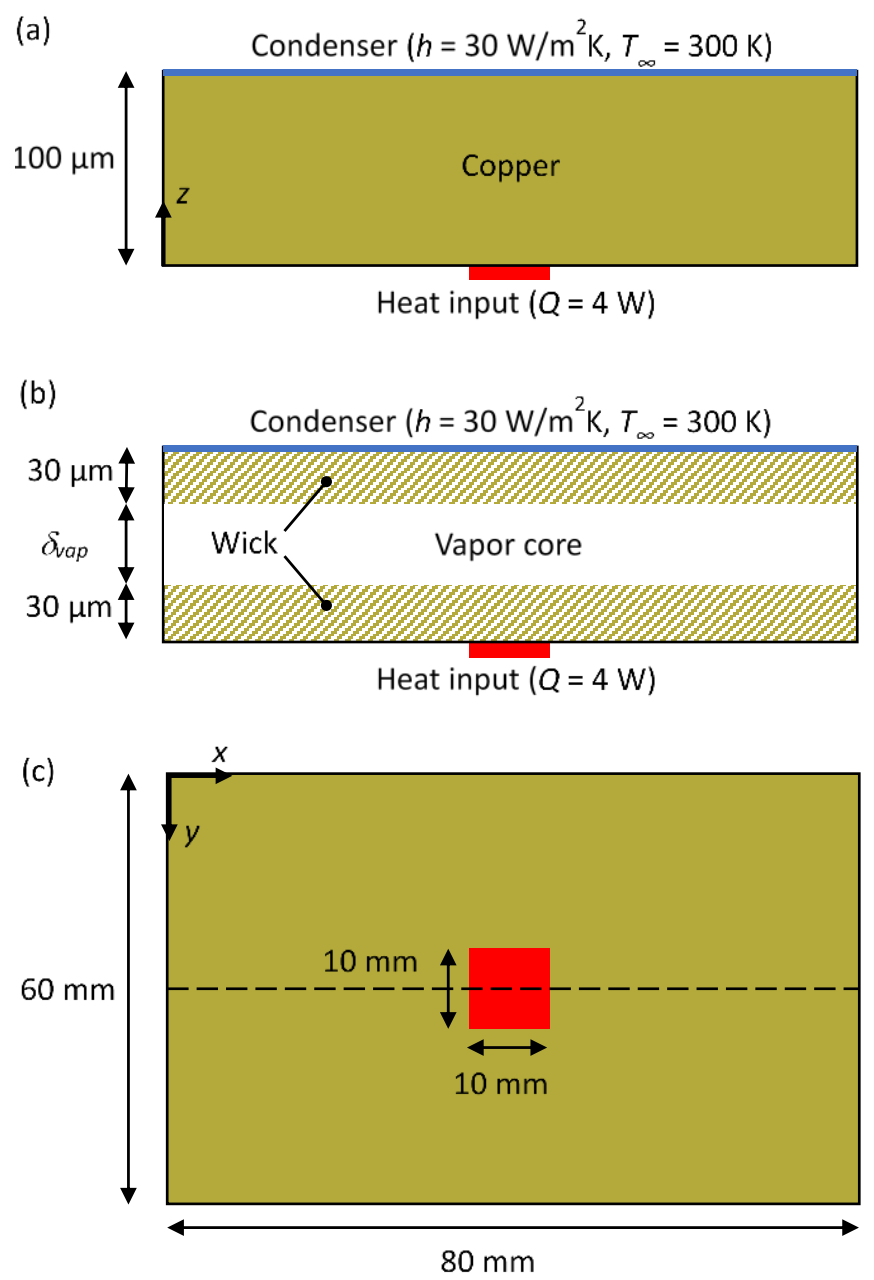

Figure 2. Geometry (not to scale) and boundary conditions for the transient heat spreading simulations showing (a) a section view for the copper spreader case, (b) a section view for the vapor chamber case, and (c) a bottom view of the evaporator-side that is common to both cases. 


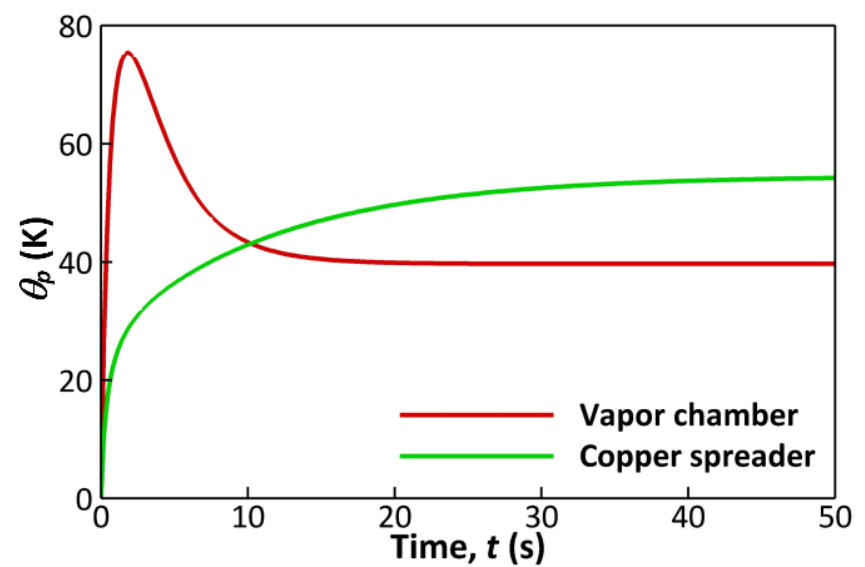

(a)

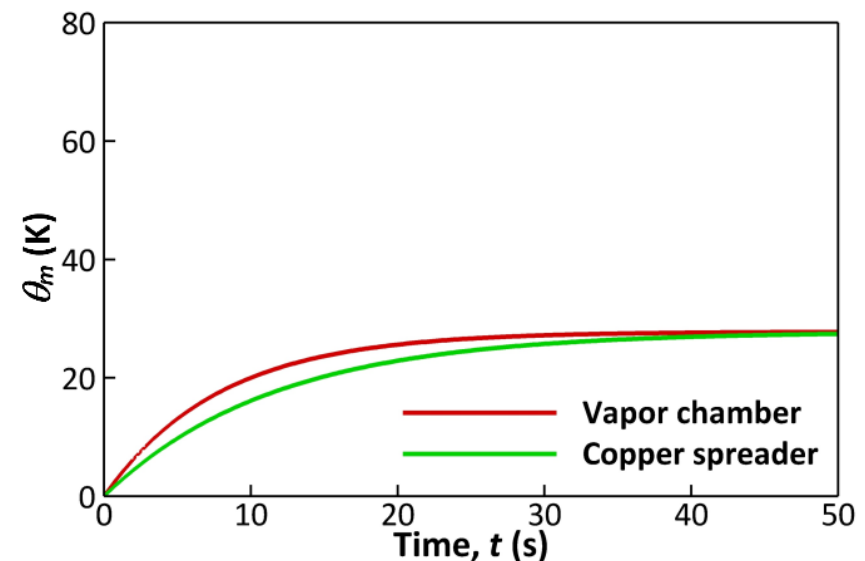

(b)

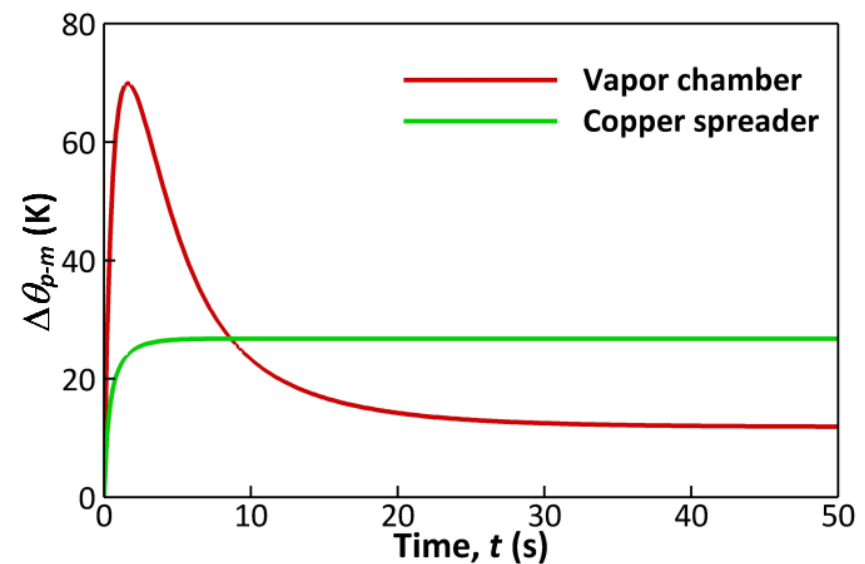

(c)

Figure 3. Comparison between the vapor chamber and the copper spreader simulation results $\left(\delta_{v a p}=40 \mu \mathrm{m}\right)$ showing the temporal variation of the (a) peak temperature $\theta_{p},(\mathrm{~b})$ volumeaveraged mean temperature $\theta_{m}$, and (c) difference between the peak and mean temperatures $\Delta \theta_{p-m}$ $=\theta_{p}-\theta_{m}$. 


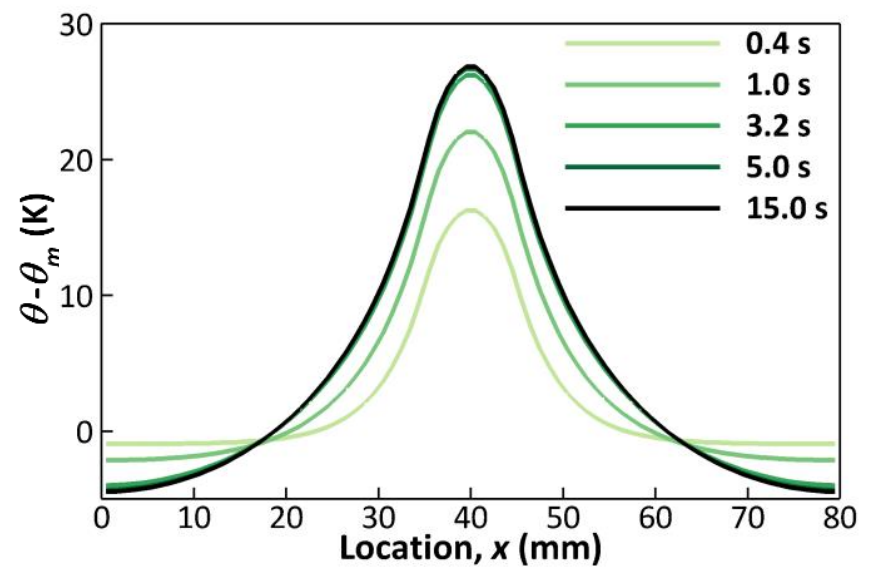

(a)

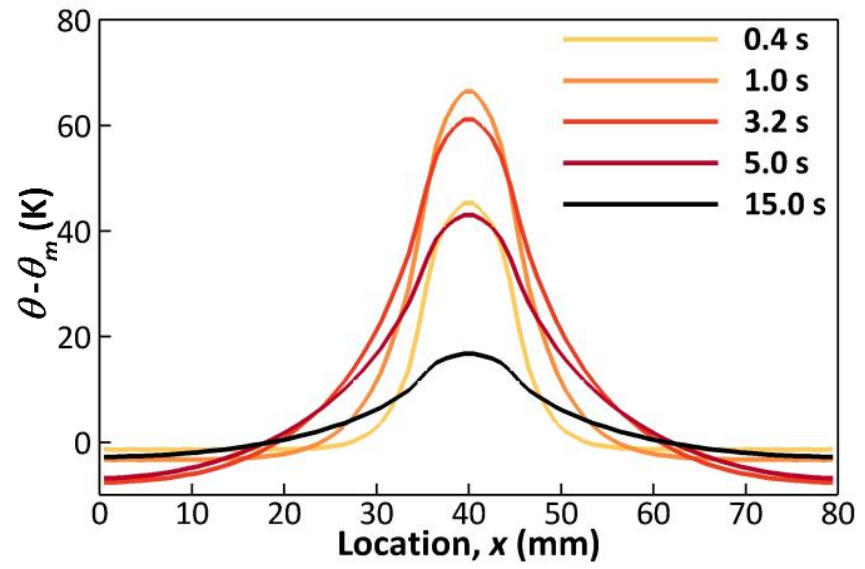

(b)

Figure 4. The profile of local temperature difference from the mean $\left(\theta-\theta_{m}\right)$ along a line on the evaporator-side surface of the heat spreader (dashed line in Figure $2 \mathrm{c}$ ) at different times, for (a) the copper spreader and (b) the vapor chamber. Note the different scales of the vertical axis for (a) and (b). 
(a)

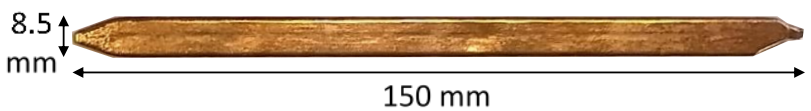

(b)

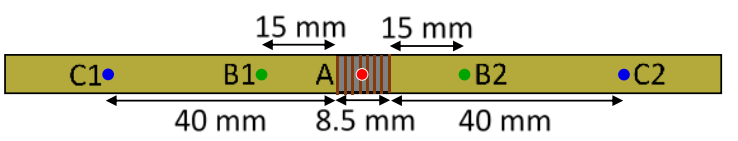

(c)

Sheathed

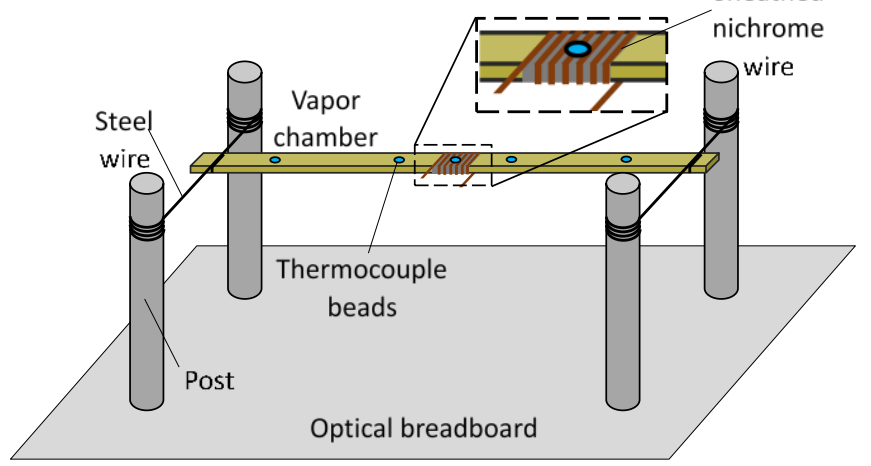

Figure 5. (a) Photograph of the vapor chamber sample in top view, (b) diagram of the locations of the thermocouple beads and heated length, and (c) illustration of the experimental test setup. 


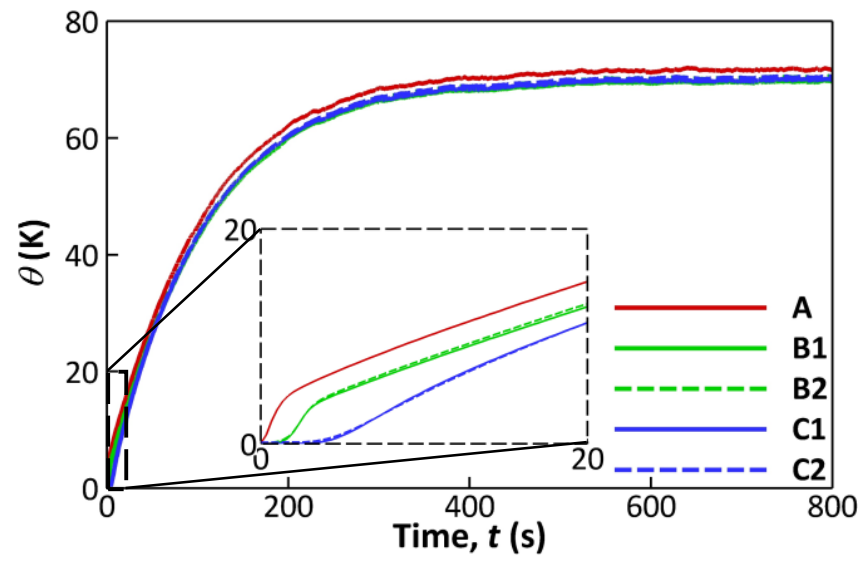

Figure 6. Experimental measurements of the temperature $\theta$ at the five thermocouple locations as a function of time. 


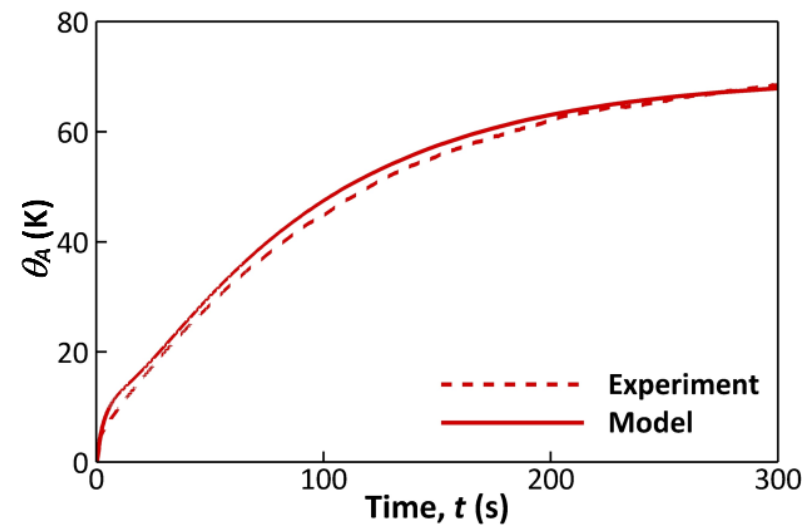

(a)

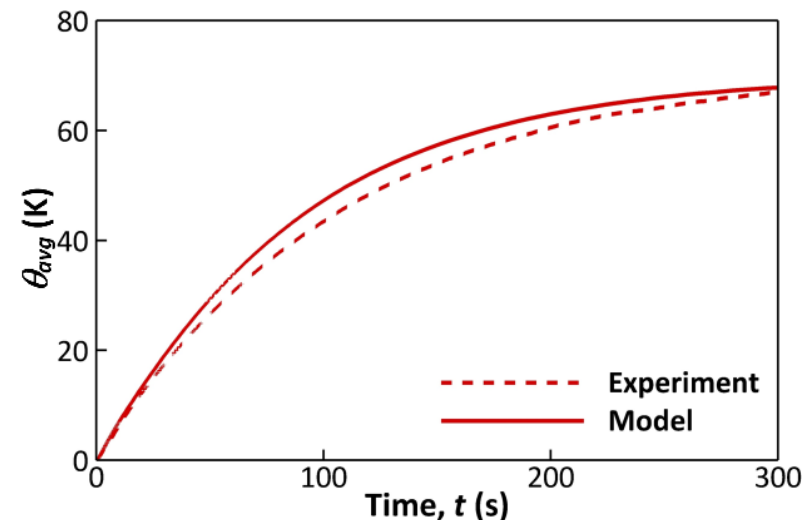

(b)

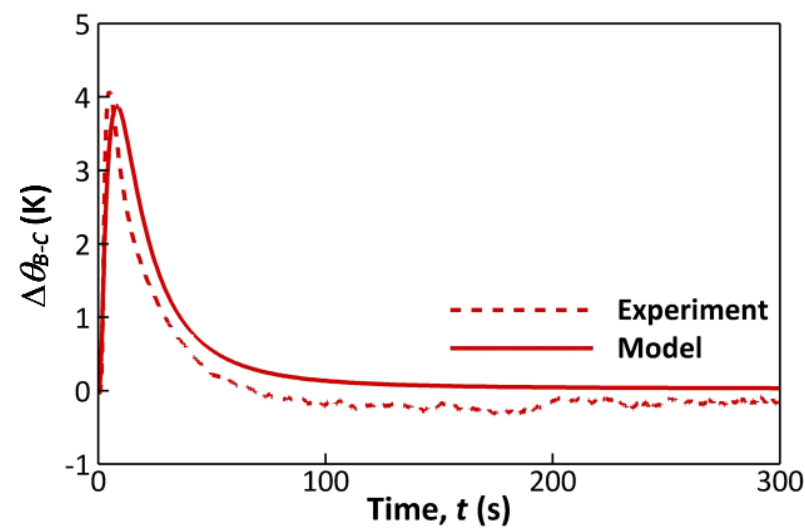

(c)

Figure 7. Comparison of the experiment and simulation: (a) temperature at thermocouple location $A\left(\theta_{A}\right)$, (b) average surface temperature relative to the ambient temperature $\left(\theta_{\text {avg }}\right)$, and (c) the average difference between the temperatures at $B$ and $C\left(\Delta \theta_{B-C}\right)$. 


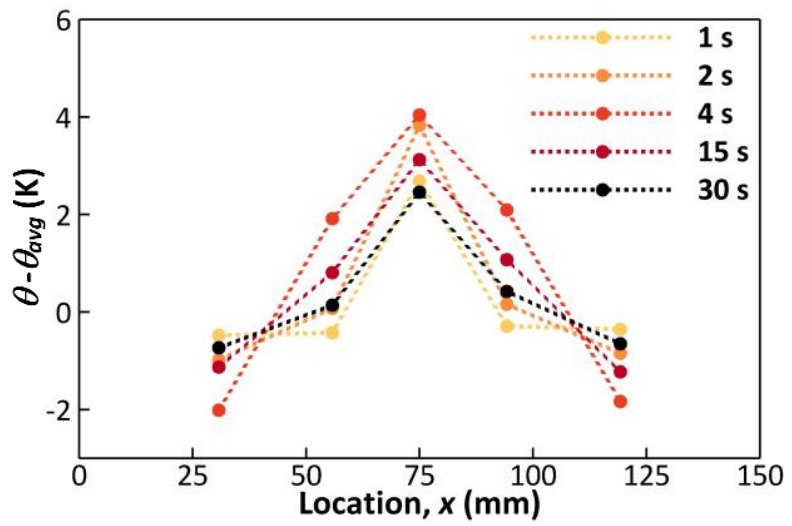

(a)

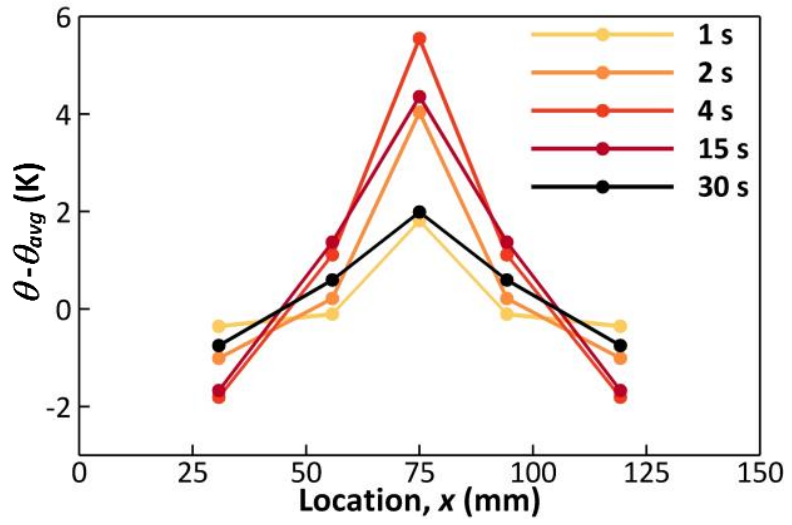

(b)

Figure 8. Vapor chamber local surface temperatures difference from the average surface temperature $\left(\theta-\theta_{\text {avg }}\right)$ at the thermocouple locations at different times from (a) the experiment and (b) the simulation. 


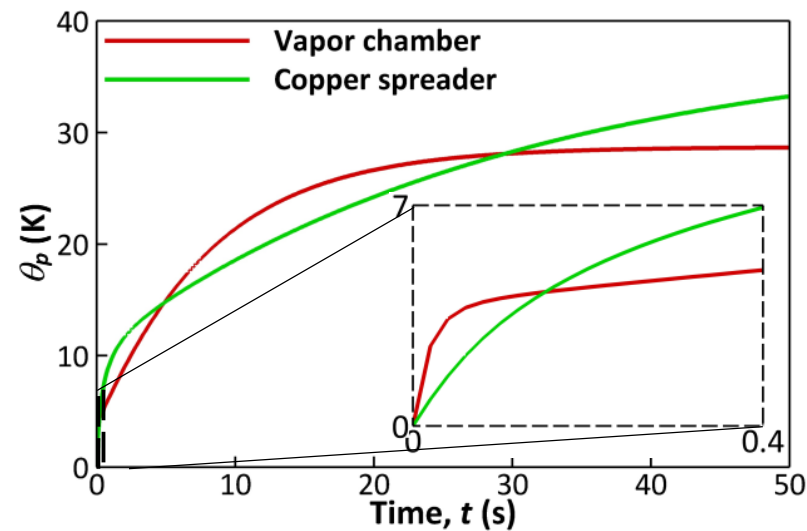

(a)

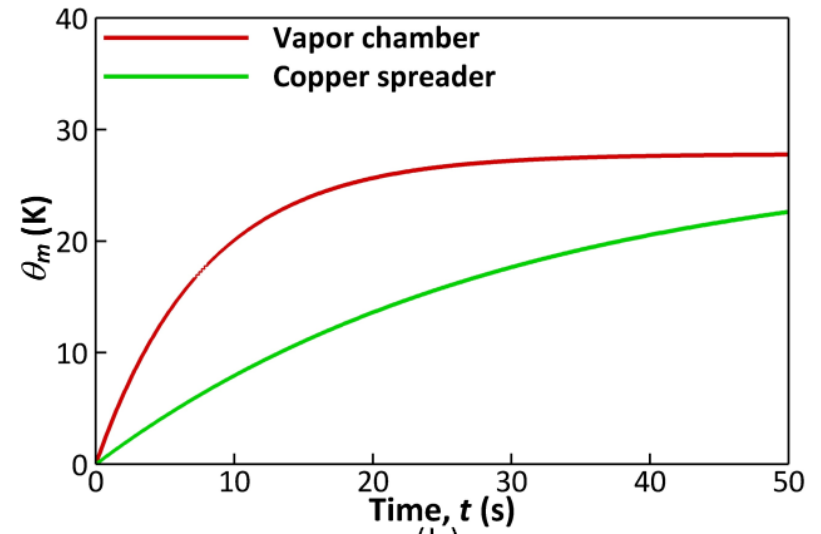

(b)

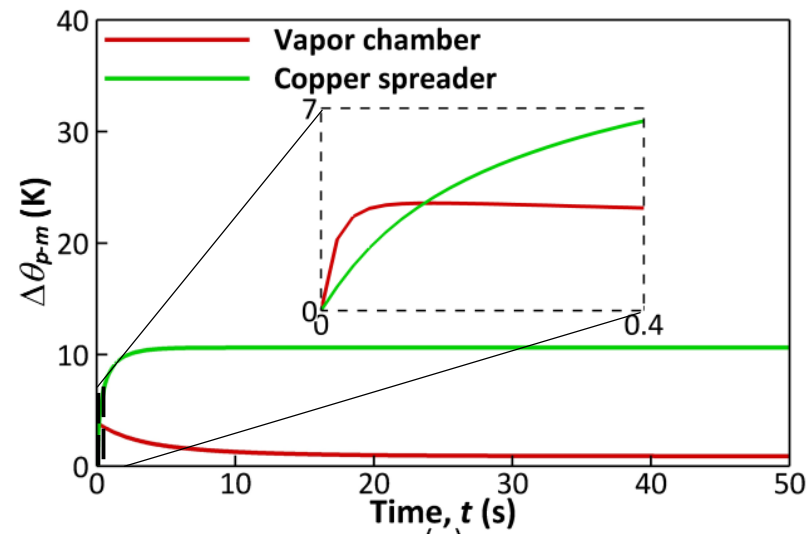

(c)

Figure 9. Comparison between the vapor chamber and the copper spreader simulation results $\left(\delta_{\text {vap }}=200 \mu \mathrm{m}\right.$ ) showing the temporal evolution of (a) peak temperature $\theta_{p}$, (b) volume-averaged mean temperature $\theta_{m}$, and (c) difference between the peak and mean temperatures $\Delta \theta_{p-m}=\theta_{p}$ - 


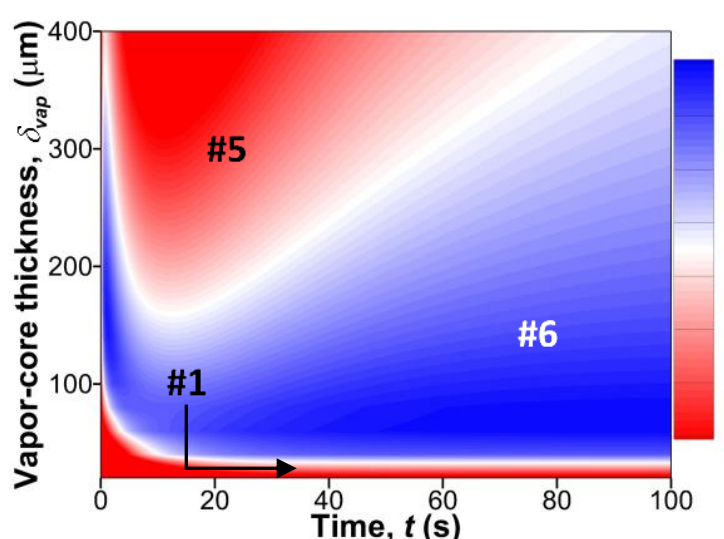

(a)

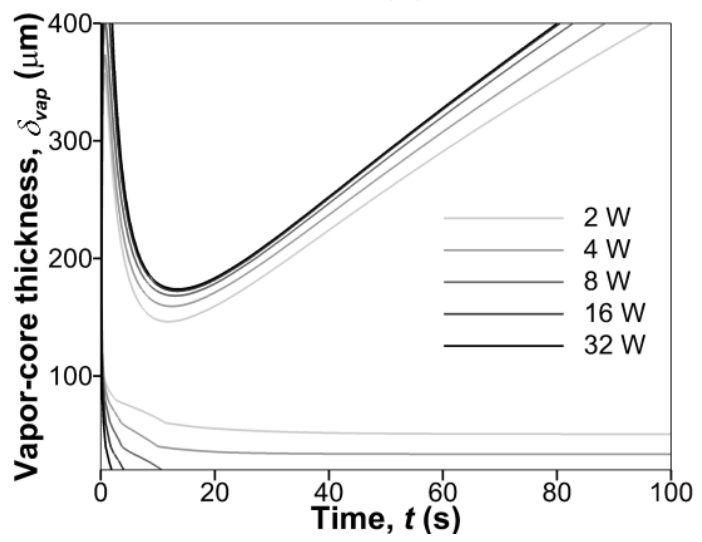

(c)

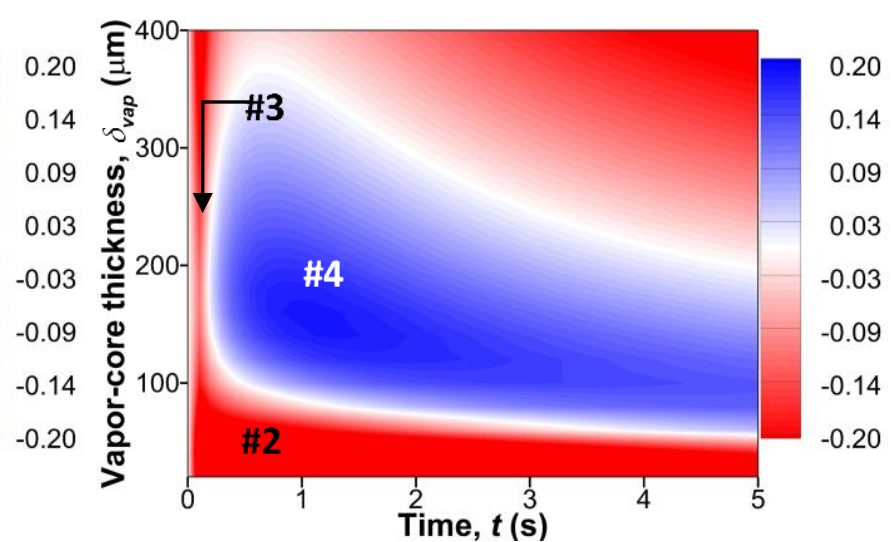

(b)

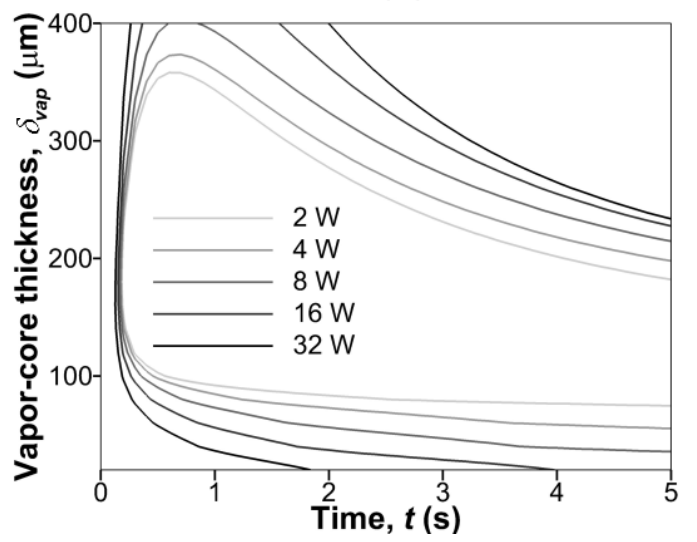

(d)

Figure 10. Contour plot of the metric for the thermal performance of a vapor chamber relative to a copper spreader $\left(M_{V C-C u}\right)$, for a range of vapor core thicknesses, and as a function of time for (a) $t<100 \mathrm{~s}$ and (b) a zoomed-in view for $t<5 \mathrm{~s}$. Threshold lines $\left(M_{V C-C u}=0\right)$ for the thermal performance of a vapor chamber relative to that of a copper spreader as a function of time for a range of vapor core thicknesses at different input powers in the range (c) $t<100 \mathrm{~s}$ and (d) a zoomed-in view for $t<5 \mathrm{~s}$. 